\title{
PENGARUH KARAKTER KEWIRAUSAHAAN TERHADAP KEMAMPUAN USAHA DI SEKTOR HORTIKULTURA PROVINSI JAWA BARAT
}

\author{
EFFECT ON THE ABILITY OF ENTREPRENEURSHIP CHARACTERHORTICULTURE \\ BUSINESS IN WEST JAVA PROVINCE
}

\author{
Yuliana Samantha, Ronnie S. Natawidjaja, Tuhpawana P. Sendjaja \\ Fakultas Pertanian Unpad, yuliana.samantha@gmail.com \\ Fakultas Pertanian Unpad, ronnie_sn@unpad.ac.id \\ Fakultas Pertanian Unpad, tuhpawana.s@unpad.ac.id
}

\begin{abstract}
Most of Indonesia's population depend on agriculture. Agriculture is the basis for growth in the countryside. Horticultural company is a company form of business or legal entity that is engaged in the cultivation or breeding and marketing of vegetables, fruit, and ornamental plants.

The research design used quantitative descriptive technique and take a case in Horticultural Company incorporated in the province of West Java. Informants research is the founder of 35 businesses horticultural businesses. Respondents were selected by simple random sampling method Solvin. Data were analyzed with path analysis, the business environment variables, entrepreneurial character, the ability of businesses and business improvement.

Character of business founders age at age less than 54 years, including age. Average of the last education strata 1 (undergraduate). A conducive business environment and the higher the entrepreneurial character can give the effect of an increase in the ability of the business. These effects are direct and indirect, of the path of the business environment $78.3 \%, 19.2 \%$ and entrepreneurial character. The effects of both variables $83.7 \%$ with $4 \%$ residual business capabilities and $16.3 \%$ influenced by other variables that are not covered.
\end{abstract}

Kata Kunci : business environment, the character of entrepreneurship, business improvement, path analysis, company, horticulture

\section{PENDAHULUAN}

Ada beberapa alasan penting yang mendasari pentingnya pertanian dalam perekonomian nasional, antara lain bahwa sebagian besar penduduk menggantungkan hidupnya pada sektor pertanian, potensi sumberdaya alam yang besar dan beraneka ragam, pertanian juga merupakan basis pertumbuhan di pedesaan dimana bangsa Indonesia sebagian besar penduduknya berada di pedesaan sehingga sektor pertanian merupakan sektor utama yang dikembangkan sebagai fondasi ekonomi Indonesia.

Dalam dunia usaha terbagi menjadi dua sektor menurut formalitasnya, yakni sektor formal dan informal. Baik dari kedua sektor memberikan konstribusi pada penyerapan tenaga kerja dan pertumbuhan ekonomi nasional.

Pertumbuhan industri kecil sangat diperlukan adanya iklim yang kondusif, Undang-Undang No. 9 tahun 1995 tentang usaha kecil menyebutkan bahwa iklim usaha adalah kondisi yang diupayakan pemerintah berupa penetapan berbagai peraturan perundangan dan kebijakan diberbagai aspek kehidupan ekonomi agar usaha kecil memperoleh kepastian, kesempatan yang sama dan dukungan berusaha yang seluas-luasnya sehingga berkembang menjadi usaha yang tangguh dan mandiri. Pemerintah berperan penting menyangkut kebijakan-kebijakan yang 
diterapkan dikalangan pengusaha, kemudahan mendirikan usaha, kebijakan terkait perdagangan ekspor dan impor. Pemerintah memberikan dukungan, yaitu mengurangi biaya dalam membuka perusahaan baru serta regulasi yang memudahkan pembukaan usaha oleh pengusahabaru.

Dikutip dalam Doing bussines (2012) di setiap negara memiliki peringkat kemudahan membangun usaha baru diurut berdasarkan kemudahan mengurus prosedur izin usaha, biaya pendirian usaha dan waktu mendirikan usaha formal.

Meningkatnya peringkat kemudahan
membangun usaha diiringi dengan
meningkatnya angka investasi yang menjadi
gambaran produktif suatu negara, karena
perekonomian di suatu negara terukur dengan
pertumbuhan dan perputaran ekonomi mikro
yang menjadi tonggak dari ekonomi makro di
Indonesia.

\section{Identifikasi Masalah}

Berdasarkan uraian pada latar belakang, maka dirumuskan permasalahan sebagai berikut : Bagaimana kontribusi lingkungan usaha terhadap kemampuan usaha.

\section{BAHAN DAN METODE}

Objek dalam penelitian ini adalah pendiri usaha hortikultura.Penelitian dilaksanakan di Jawa Barat.Desain penelitian yaitu penelitian kuantitatif.Metode yang digunakan summated rating dengan model skala Likert's.

Penetapan sampel dalam penelitian ini dilakukan dengan menggunakan Simple Random Sampling. Populasi dalam penelitian ini adalah perusahaan hortikultura berbadan hukum berdasarkan data Badan Pusat Statistik 2011. Agar pendugaan terhadap populasi bersifat baik, maka sampel yang diambil tidak kurang dari 30 sampel atau $10 \%, 15 \%$, dan $20 \%$ dari jumlah keseluruhan populasi (Gasperz, 2010). Oleh karena itu, peneliti menghitung sampel dengan menggunakan rumus: $\mathrm{n}=\frac{\mathrm{N}}{1+\mathrm{N}(\mathrm{e})^{2}}$.

Dimana: $\mathrm{n}=$ Jumlah sampel

$\mathrm{N}=$ Ukuran populasi

$\mathrm{E}=$ Batas kekeliruan (bound of error) yang

digunakan $10 \%$

maka jumlah sampel minimal yang dibutuhkan dalam penelitian yaitu 35perusahaan.

\section{Metode Analisis}

Fungsi regresi linier dapat ditulis sebagai berikut:

$\mathrm{Y}=\rho \mathrm{YX}_{1}+\rho \mathrm{YX}_{2}+\epsilon$

Dimana:

$\mathrm{Y}=$ Kemampuan Usaha

$\rho \mathrm{YX}_{1}=$ usia pohon

$\rho \mathrm{YX}_{2}=$ koefisien jalur karakter kewirausahaan

$\epsilon \quad=$ residu

Selanjutnya untuk mengkaji apakah faktor-faktor produksi yang digunakan secara bersama-sama berpengaruh terhadap kemampuan usaha digunakan Uji $\mathrm{F}(F$ test).Pengaruh dari masing-masing faktor terhadap kemampuan usaha digunakan uji koefisien regresi dengan uji t.

Untuk mengetahui apakah suatu alat ukur benar-benar mengukur apa yang ingin diukur dilakukan pengujian sebagai berikut:

\section{a. Pengujian Validitas}

Metoda yang digunakan untuk menguji validitas masing-masing pernyataan terhadap instrumen kuesioner,menurut Arikunto (2010)

\section{b. Pengujian Reabilitas}

Untuk menguji reliabilitas digunakan rumus alfa (Cronbach's Alpha, yaitu uji reliabilitas untuk alternatif jawaban lebih dari dua.

\section{HASIL DAN PEMBAHASAN}

\section{Lingkungan Usaha}

\section{Lokasi Perusahaan}

Lokasi perusahaan kondusif, letak perusahaan dengan akses pasar untuk bahan produksi ataupun untuk pemasaran. Tenaga kerja diambil dari desa/kecamatan/kabupaten lokasi usaha baik tenaga terampil/terlatih, terdidik, dan terdidik dan terlatih. 
Fasilitas transportasi atau jarak lokasi perusahaan dengan jalan raya provinsi kurang dari 200m. Sumberdaya Alam, keadaan tanah, air, dan iklim yang mendukung produksi. Dan sikap masyarakat setempat yang mendukung adanya usaha.

\section{Akses Kredit/Modal}

Dalam penelitian ini karena umumnya lokasi produksi di daerah Kabupaten dan manajemen keuangan di daerah Kota Provinsi, akses permodalan untuk perusahaan hortikultura yang dominan produksi memiliki akses modal di lokasi setempat yang kurang kondusif tergambar dari adanya badan keuangan yang mampu memberikan keuangan di lokasi setempat ada kurang dari tiga badan keuangan perbankan ataupun non perbankan, berbeda dengan perusahaan trading atau pemasaran yang memang berdomisili di lokasi perkotaan dan memiliki akses sampai lebih dari lima tempat badan keuangan untuk mendapat kredit baik perbankan maupun non perbankan.

Umumnya pendiri usaha, direktur utama dan manajer perusahaan sudah tahu bagaimana prosedur mendapatkan kredit.

\section{Informasi dan Jaringan Usaha}

Pendiri usaha telah mengikuti asossiasi dan organisasi yang bergerak dibidang hortikultura contohnya Perhimpunan Anggrek Indonesia (PAI) dan bermitra dengan Proyek Peningkatan Pendapatan Petani Kecil (P4K). Pendiri usaha dalam menyalurkan produk juga banyak bermitra dengan petani daerah sekitar didasari moral ingin mengebangkan potensi jual petani untuk perusahaan hortikultura yang bergerak di komoditas sayuran.

\section{Prosedur Perizinan}

Prosedur perizinan saat ini sudah mulai dipermudah oleh pemerintah, ada sebagian yang mengaku bahwa sekarang dengan satu pintu sudah dapat selesai, atau syarat dan ketentuan diserahkan kepada notaris kedua prosedur ini memakan waktu kurang dari dua minggu, sebagian berpendapat bahwa mudahnya perizinan prosedur usaha melalui tiga kementrian terkait, kementrian pertanian, kementrian industri dan kementrian perdagangan, dan untuk perusahan-perusahaan besar dan memiliki umur pembentukan usaha disadari kendala terdapat pada waktu dan biaya yang dikeluarkan perusahaan.

Prosedur perizinan usaha untuk Yayasan disatukan dengan prosedur pembentukan yayasan tersebut sehingga prosesnya tidak melebihi waktu tiga hari.

Pembentukan usaha bagi perusahaan memberikan kemudahan mengimpor bahan baku dari luar, contoh untuk bunga, bibit lily dan carnation langsung diimpor dari Belanda, dan untuk sayuran asparagus dan sebagainnya. Ada perusahaan yang berpendapat bahwa biaya impor memiliki biaya pungutan selain biaya resmi yang ditetapkan, dan perusahaan sempat mengalami kerugian karena bibit tersebut ditahan oleh pihak-pihak yang tidak bertanggungjawab, sendangkan untuk perusahaan eksportir mengaku bahwa prosedur yang ada memudahkan perusahaan untuk mengekspor produknya.

\section{Pajak}

Pajak yang dibebankan oleh negara kepada perusahaan dianggap tidak membebani, menurut perusahaan apalagi jika pajak tersebut disalurkan kepada program-program pemerintah yang tepat guna, perusahaan tidak keberatan menyisihkan biaya untuk membayar pajak.

\section{Karakter Kewirausahaan Pendiri Usaha \\ Menurut Cantillon dalam Ciputra (2009), entrepreneur ialah mereka yang membayar harga tertentu untuk produk tertentu, untuk dijual dengan harga yang tidak pasti, diiringi keputusan-keputusan tentang upaya mencapai dan memanfaatkan sumber daya, dan menerima risiko berusaha.}


Menurut Smith dalam Ciputra (2009), entrepreneur ialah sebagai individu yang menciptakan suatu organisasi untuk tujuantujuan komersial.Entrepreneurberaksi terhadap perubahan-perubahan ekonomi, bahkan entrepreneur merupakan bagian dari perubahan ekonomi.

Unsur-unsur Definisi koordinasi kewirausahaan yaitu sumberdaya, penciptaan bisnis baru, dan inovasi tidak menunjukkan hubungan antara kewirausahaan dan peningkatan usaha.

\section{Motivasi}

Pendiri usaha tidak turun langsung dalam proses manajemen produksi, dan motivasi untuk mengembangkan usaha tidak tumbuh pada pendiri usaha, pendiri usaha sudah berada diposisi yang menurutnya titik puncak usaha sehingga tidak berminat untuk mengembangkan lagi. Pendiri usaha menyerahkan pekerjaan yang tidak dapat ditanganinya ke tangan para ahli. Pendiri usaha mengawasi perkembangan usaha melalui laporan pembukuan.

\section{Inovasi}

Perusahaan mampu mengadaptasi teknologi yang berkembang di sektor hortikultura diantaranya: Adaptasi teknologi yaitu penggunaan rumah kaca, penggunaan media tanam cocopit, kepemilikan gudang penyimpanan berupa cold storage, pengadaan bibit unggul baik impor ataupun kerjasama dengan instansi dan universitas terkait dan rekayasa pengemasan atau packaging.

Beberapa perusaha sayuran dan bunga menggunakan teknik plug atau teknik pembibitan dalam sel tanaman berukuran kecil yang memberikan pertumbuhan cepat, seragam dan hemat. Teknik pembibitan stek menjadi teknik budidaya yang dikembangkan untuk bibit krisan, terbagi kedalam dua teknik yaitu stek batang dan stek pucuk.

\section{Keberanian Mengambil Risiko}

Pengusaha juga tidak senang mengambil risiko yang tidak dapat diduga oleh pendiri, diluar dari risiko yang muncul, pendiri usaha yang sudah terbiasa dengan risiko pemasaran di lingkup domestik tidak ada keinginan untuk memperluas usahanya ke lingkup nasional atau internasional karena dianggap ada risiko lain yang akan dihadapi diluar risiko yang mampu diprediksi pengusaha selama ini, sehingga dititik tertentu pegusaha akan merasa nyaman dan merasa cukup dengan pangsa pasar yang sudah diraih.

Risiko pemasaran yang terjadi yaitu pelaku ritel ataupun eksportir tidak membayar hasil produksi ataupun menyalahi kontrak yang disepakati.

\section{Kemampuan Usaha}

Lingkungan usaha telah menunjukkan kontribusi positif. Naude (2008) menyatakan beberapa cara terbaik untuk mendukung entrepreneurship antara lain meningkatkan kemampuan entrepreneur dan mengurangi biaya dalam membuka perusahaan baru serta regulasi yang memudahkan pembukaan usaha oleh entrepreneur baru.

Kemampuan entrepreneur menentukan pembangunan ekonomi suatu negara. Negara tidak hanya memperhitungkan berapa banyak entrepreneur yang lahir, tetapi juga kapabilitas mereka agar stabilitas ekonomi makro lebih terkendali.

Naude (2008) menyatakan beberapa cara terbaik untuk mendukung entrepreneurship antara lain meningkatkan kemampuan entrepreneur dan mengurangi biaya dalam membuka perusahaan baru serta regulasi yang memudahkan pembukaan usaha oleh entrepreneur baru. Negara-negara tidak hanya memperhitungkan berapa banyak entrepreneur yang lahir, tetapi juga kapabilitas mereka agar stabilitas ekonomi makro lebih terkendali.

\section{Investasi}

Menurut Sugiharto (2002), dalam melakukan investasi tersebut setiap perusahaan umumnya akan berusaha agar perluasannya dapat berkembang sesuai dengan tujuan 
perusahaan yaitu untuk mendapatkan laba sebesar-besarnya untuk kelangsungan hidup perusahaan.

\section{Produktivitas}

Menurut Soetomo (2009), peningkatan nilai produksi berbanding lurus dengan peningkatan distribusi tenaga kerja yang terlibat dalam sektor tersebut, sehingga apabila terjadi peningkatan investasi pada berbagai sektor pembangunan, selain terjadi peningkatan produksi juga berpengaruh terhadap penyerapan tenaga kerja.

Pengembangan investasi untuk berbagai sektor akan membutuhkan tenaga kerja produktif yang memadai.

\section{Peningkatan Lahan}

Suparmoko (2002) mendefinisikan sumberdaya lahan(land resources)sebagai lingkungan fisik terdiri dari iklim, relief, tanah, air danvegetasi serta benda yang ada di atasnya sepanjang ada pengaruhnya terhadappenggunaan lahan. Oleh karena itu sumberdaya lahan dapat dikatakan sebagai ekosistem karena adanya hubungan yang dinamis antara organisme yang ada di atas lahan tersebut dengan lingkungannya.

\section{Hubungan Lingkungan Usaha, Karakter Kewirausahaan Terhadap Kemampuan Usaha}

Dalam penelian ini, penulis menggunakan aplikasi SPSS ver. 21 untuk mengetahui pengaruh lingkunganusaha dan karakter kewirausahaan terhadap kemampuan usaha maka hasil regresi linier pada penelitian ini adalah:

Tabel 1. Pengaruh Parsial Lingkungan Usaha dan Karakter Kewirausahaan Terhadap Kemampuan Usaha

\begin{tabular}{|c|c|c|c|c|c|}
\hline \multirow[t]{2}{*}{ odel } & \multicolumn{2}{|c|}{ nstandardized Coefficients } & \multirow{2}{*}{$\begin{array}{c}\text { tandardized } \\
\text { eta }\end{array}$} & & \multirow[t]{2}{*}{ ig. } \\
\hline & & td. Error & & & \\
\hline & 7,767 & 039 & & 7,472 & 000 \\
\hline$\left(\mathrm{X}_{1}\right)$ &, 153 & 367 & 783 &, 591 & 000 \\
\hline$\left(\mathrm{X}_{2}\right)$ & 574 & 273 & 192 &, 106 & 043 \\
\hline
\end{tabular}

Tabel 2. Hasil Analisis Pada Koefisien jalur Lingkungan Usaha dan Karakter Kewirausahaan Terhadap Kemampuan Usaha Secara Parsial

\section{a. Koefisien Determinasi $\left(\mathbf{R}^{2}\right)$}

Dari hasil analisis diketahui nilai koefisien determinasi sebesar 0,837 atau dapat dikatakan bahwa $83,7 \%$ kemampuan usaha dipengaruhi oleh faktor lingkungan usaha dan karakter kewirausahaan yang diteliti. Sedangkan $16,3 \%$ dipengaruhi oleh faktor lain yang tidak termasuk dalam variabel penelitian.

\section{b. Uji F}

Uji F digunakan untuk menguji hubungan faktor produksi secara bersama-sama terhadap produksi yang dihasilkan, dengan taraf signifikansi $\alpha=0,05$. Hasil analisis kemampuan usaha dapat dilihat pada Tabel 1.Bahwa probabilitas F statistic sebesar 0,000000.Dengan tingkat 95\% maka hipotesis nol ditolak karena nilai probabilitas F-statistik lebih kecil dari $\alpha$ yang artinya variabel independen secara bersama-sama berpengaruh terhadap produksi. 


\section{c. Uji t}

Uji t digunakan untuk mengetahui pengaruh dari masing-masing lingkungan usaha $\left(\mathrm{X}_{1}\right)$ dan karakter kewirausahaan $\left(\mathrm{X}_{2}\right)$ terhadap kemampuan usaha (Y).Hasil analisis uji t pada pendiri usaha di Jawa Barat dapat dilihat dalam Tabel 2.

Dapat diketahui bahwa variabel lingkungan usaha memperlihatkan adanya pengaruh positif terhadap kemampuan usaha, demikian juga untuk variabel karakter kewirausahaan.

Lingkungan bisnis memiliki peran penting terhadap kesuksesan suatu bisnis (Delmar et al, 2008). Smit et aldalam Olawale (2010), mengartikan lingkungan usaha sebagai faktor internal dan eksternal yang dapat memberi pengaruh dan kesuksesan organisasi.

\section{Pengaruh Langsung dan Tidak Langsung Lingkungan Usaha dan Karakter Kewirausahaan}

Pengaruh masing-masing variabel bersifat langsung dan tidak tidak langsung adalah sebagai berikut.

Persamaan regresi:

$$
\mathrm{Y}=0,783 \mathrm{X}_{1}+0,192 \mathrm{X}_{2}+\varepsilon
$$

- Besarnya Koefisien jalur:

$$
\begin{aligned}
& \rho_{\mathrm{YX} 1}=0,783 \\
& \rho_{\mathrm{YX} 2}=0,192
\end{aligned}
$$

- Besarnya koefisien korelasi:

$$
\begin{aligned}
& \mathrm{R}_{\mathrm{x} 1 \times 2}=0,837 \\
& \rho \text { ye }=\sqrt{(1-0,837)}=0,404 \approx 0,4
\end{aligned}
$$

- Besarnya pengaruh langsung :

1. $\mathrm{X}_{1}$ terhadap $\mathrm{Y}\left(\rho \mathrm{yx}_{1}\right)$ adalah $=0,783^{2} \mathrm{x}$ $100 \%=61,31 \%$

2. $\mathrm{X}_{2}$ terhadap $\mathrm{Y}\left(\rho \mathrm{yx}_{2}\right)$ adalah $=0,192^{2} \mathrm{x}$ $100 \%=3,69 \%$

- Besarnya pengaruh tidak langsung :

1. $\mathrm{X}_{1}$ terhadap $\mathrm{Y}$ melalui $\mathrm{X}_{2}$ adalah $=$ $0,783 \times 0,837 \times 0,192 \times 100 \%=12,58 \%$

2. $\mathrm{X}_{2}$ terhadap $\mathrm{Y}$ melalui $\mathrm{X}_{1}$ adalah $=$ $0,192 \times 0,837 \times 0,783 \times 100 \%=12,58 \%$

- Besarnya pengaruh langsung dan tidak langsung :

1. $\mathrm{X}_{1}$ terhadap $\mathrm{Y}$ adalah $=61,31 \%+12,58 \%$ $=73,89 \%$

2. $\mathrm{X}_{2}$ terhadap $\mathrm{Y}$ adalah $=3,69 \%+12,58 \%=$ $16,27 \%$

- Besarnya pengaruh total $X_{1}$ dan $X_{2}$ terhadap Y adalah 90,16\%

- Besarnya pengaruh akibat faktor lainnya yang tidak diteliti100\% - 90,16\% $=9,84 \%$

Hasil dari analisis jalur pengaruh langsung dan tidak langsung, lingkungan usaha telah memberikan kontribusi positif dan sifat iklim usaha yang kondusif untuk perkembangan

\begin{tabular}{|c|c|c|c|c|}
\hline \multirow{2}{*}{ Jalur } & \multirow{2}{*}{$\begin{array}{l}\text { Pengaruh Langsung } \\
\qquad(\%)\end{array}$} & \multicolumn{2}{|c|}{ Pengaruh Tidak Langsung (\%) } & \multirow{2}{*}{ Total $(\%)$} \\
\hline & & $\mathrm{X}_{1}$ & $\mathrm{X}_{2}$ & \\
\hline$\overline{P_{\mathrm{yx} 1}}$ & 61,31 & & 12,58 & 73,89 \\
\hline $\mathrm{P}_{\mathrm{yx} 2}$ & 3,69 & 12,58 & & 16,27 \\
\hline $\mathrm{R}^{2}$ & \multicolumn{3}{|c|}{ Pengaruh $X_{1}$ dan $X_{2}$} & 90,16 \\
\hline $1-R^{2}$ & \multicolumn{3}{|c|}{ Dipengaruhi Faktor Lainnya } & 9,84 \\
\hline Total & \multicolumn{3}{|c|}{ Total Pengaruh } & 100,00 \\
\hline
\end{tabular}
kemampuan usaha. Dapat disajikan melalui Gambar 1.

Tabel 3. Besarnya Pengaruh Langsung dan Tidak Langsung Lingkungan Usaha dan Karakter Kewirausahaan Terhadap Kemampuan Usaha 


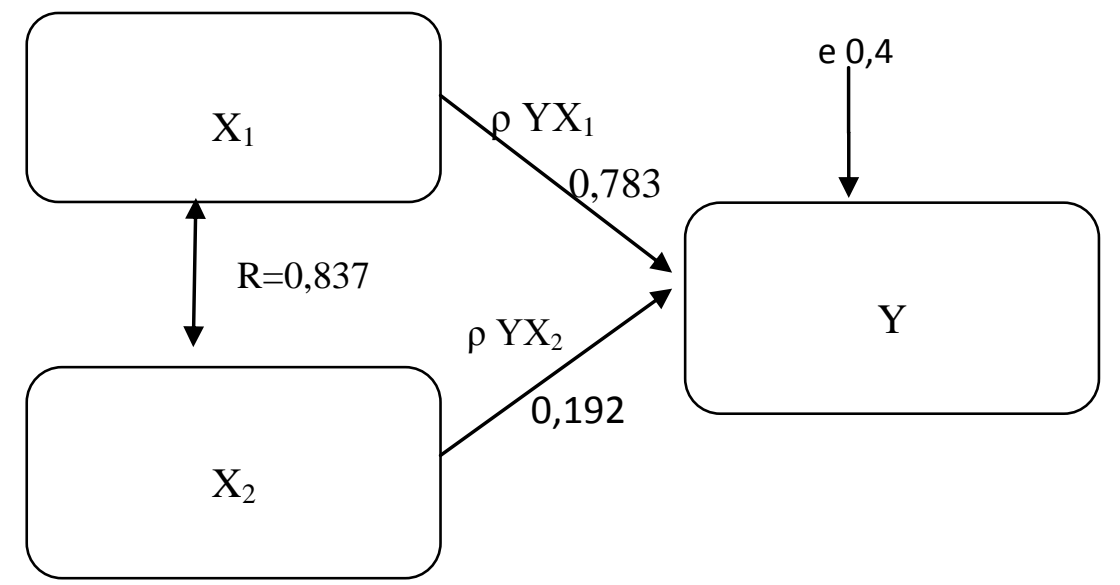

Keterangan : $\quad \mathrm{X}_{1}=$ Lingkungan Usaha

$\mathrm{X}_{2}=$ Karakter Kewirausahaan

$\mathrm{Y}=$ Kemampuan Usaha

Gambar 1. Hubungan Kausal Antara Lingkungan Usaha dan Karakter Kewirausahaan Terhadap Kemampuan Usaha

\section{Kesimpulan}

Berdasarkan hasil deskripsi dananalisis di lapanganmakadapatdiambilkesimpulansebagaiberi kut :

Lingkungan usaha memberikan kontribusi positif terhadap peningkatan bisnis hortikultura. Semakin tinggi lingkungan usaha dan karakter kewirausahaan maka akan semakin baik kemampuan usaha yang terjadi.

\section{Saran}

Saran yang dapat diberikan penulis kepada instansi terkait, praktisi, dan peneliti lebih lanjut, diantaranya:

1. Praktisi, dengan terbentuknya usaha menjadi usaha berbadan hukum, diharapkan praktisi mampu memproduksi tidak hanya untuk pemasaran dalam negeri tapi juga untuk pasar ekspor.

2. Masyarakat luas, lingkungan usaha atau iklim usaha di Provinsi Jawa Barat sesuai dengan data lapangan menunjukkan kontribusi positif, sehingga ada baiknya menyadarkan kepada masyarakat luas untuk memulai investasi bisnis sektor real dibidang hortikultura agar dapat memenuhi permintaan dalam dan luar negeri.

3. Penelitian selanjutnya, penulis menyarankan untuk mengangkat peran pemerintah dalam menangani dan memberikan perlindungan produk hortikultura pasca panen dan dalam penelitian selanjutnya disarankan untuk mengukur setiap indikator dari variabel agar indikator yang menghambat dapat ditunjukkan dan diberikan solusi selanjutnya.

\section{UCAPAN TERIMAKASIH}

Penulis mengucapkan terimakasih kepada pengusaha hortikultura yang telah bersedia untuk diwawancara, dan penelaah naskah.

\section{DAFTAR PUSTAKA}

Arikunto, S. 2010. Prosedur penelitian : Suatu Pendekatan Praktik. (Edisi Revisi). Jakarta : Rineka Cipta

Ciputra. 2009. Quantum Leap: EntrepreneurshipMengubah Masa depan Bangsa dan Masa depan Anda. Gramedia; Jakarta.

Delmar F, Wiklund J. 2008. The effect of Small Business Managers' Growth and Motivation on Firm Growth: Entrepreneurship Theory Pract.

Gasperz, Vincent. 2002. Teknik Penarikan Contoh Untuk Penelitian Survei. Tarsito. Bandung

Naude, Wim. 2008. Entrepreneurship in Economic Development, Research Paper No. 2008120. United Nations University 
Naude', W. A. 2010a. Entrepreneurship, developing countries and development economics: New approaches and insights. Small Business Economics Journal, 34(1), $1-12$.

Naude', W. A. 2011. Entrepreneurship is not a Binding Contraint on Growth and Development in the Poorest Countries. World Development Journal, 39(1), 3344

Olawale, F. 2010. Obstacles to the growth of new SMEs in South Africa: A principal component analysis approach. African Journal of Business Management, 4(5), 729-738.

Soetomo. 2009. Analisis Peningkatan Iklim Investasi sebagai Upaya Peningkatan Peluang Kerjasama Investasi Antar Daerah di Kabupaten Nganjuk. JAMBSP Vol. 5 No. 2 - Februari 209: 16- 184.

Sugiharto, Toto. 2002. Studi Kelayakan Proyek Pengembangan Perkebunan Pisang Abaca dengan Menggunakan Analisis PeranggaranModal, Jurnal Ekonomi dan Bisnis, Jilid 7, No. 3:145-150.

Suparmoko. 2002, Penilaian Ekonomi: Sumberdaya Alam dan Lingkungan, Yogyakarta: BPPE.

Undang-undang Pemerintah no 20 tahun 2008 tentang Usaha mikro.

Undang-Undang Republik Indonesia Nomor: 9 tahun 1995 tentang Usaha Kecil

Penulis Pertama adalah Staf pengajar di Fakultas Pertanian Unwim, Penulis Kedua dan Ketiga adalah staf pengajar di Fakultas Pertanian Unpad 